\title{
Looking at the face of the Earth
}

\author{
A sixteenth-century Dutch master's carefully orchestrated winter landscape may have benefited from his \\ knowledge of geographers' techniques of the time, explains Martin Kemp.
}

Old-master paintings are now conspicuous among the array of Christmas cards. Museums and galleries vigorously market cards based on their holdings of Madonnas, adorations and winter landscapes. Probably no 'secular' subject is more popular than Pieter Bruegel's great vista of Winter (1565), often called Hunters in the Snow.

The painting shows the hunters, one bearing the meagre corpse of a fox, trudging heavily across the top of a wooded hill accompanied by weary dogs, all silhouetted against the stark snow. Below, in panoramic array, a landscape unfolds, marked indelibly by human presence and the ordering activity of irrigation and agriculture.

To the left, peasants bring bundles of faggots to a blazing fire outside an inn. The inn sign "This is the Hart" - hangs askew. It depicts, schematically, St Hubert witnessing his vision of the crucified Christ between the antlers of a stag. Diminutive figures of skaters, curlers and spinners of tops play on the frozen ponds. Black birds punctuate the gloomy skies.

This was a new kind of picture, a new way of looking at Earth and its inhabitants. Fascinatingly, one of Bruegel's great friends was the geographer Abraham Ortelius, whose famous maps disseminated the Renaissance cartographers' new ways of envisaging the world. Ortelius's 1573 epitaph for Bruegel, written four years after the painter's death, leaves us in no doubt about his opinion: "No one except through envy, jealousy or ignorance of that art will ever deny that Peter Bruegel was the most perfect painter of this century." Ortelius suggests that Bruegel's untimely death might be attributed to "Nature's fear that his ingenious artifice in imitation would bring her into contempt".

Ortelius and Bruegel were in related branches of a Ptolemaic project. Ptolemy distinguished between geography and chorography in the second century. The former was concerned with "the mapping of countries", the latter with "smaller divisions". Geography, by analogy, is "concerned with the depiction of the entire head", whereas chorography involves itself with "individual features, such as an eye or ear". Bruegel is the great master of the facial features that characterize Earth.

Bruegel is profoundly involved in acts of articulate seeing. He has perfectly captured the way that the glare of the snow suppresses much of the internal detail of colour and

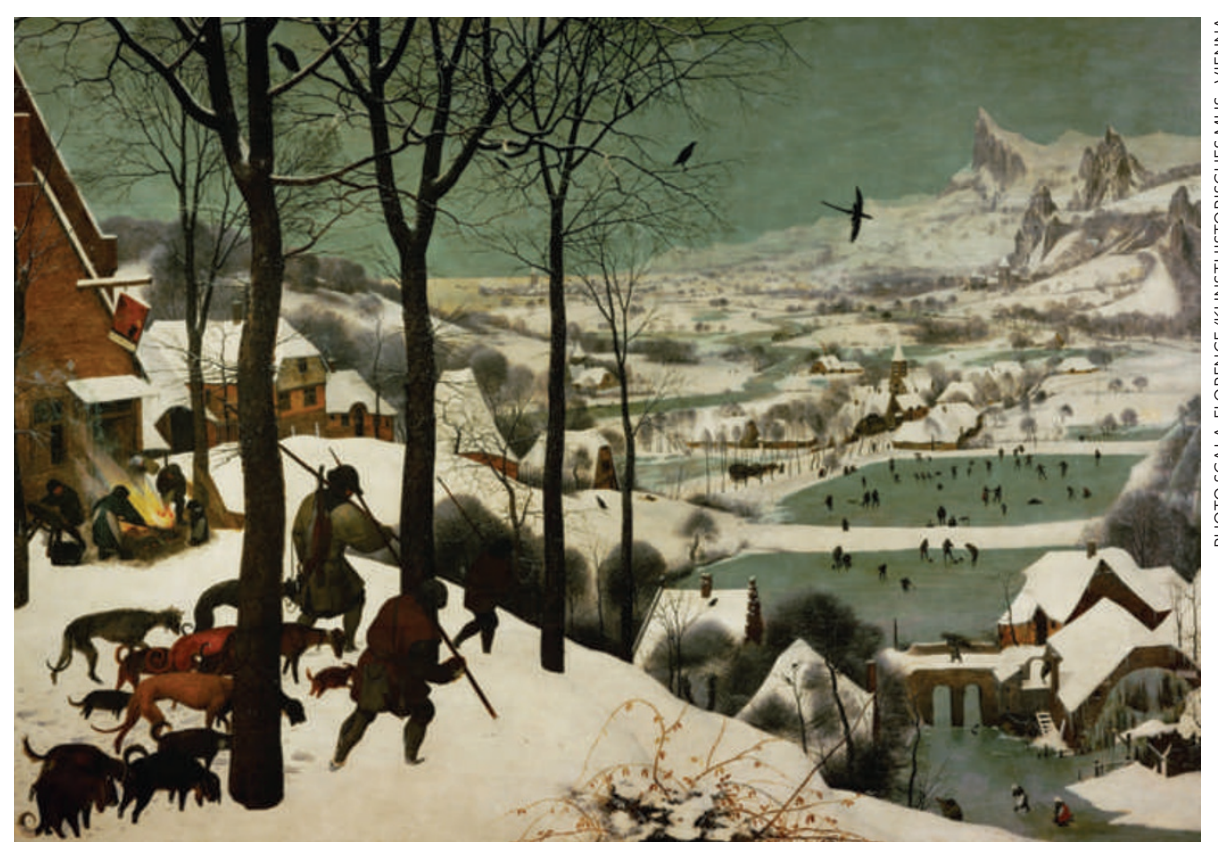

Pieter Bruegel's wintry scene is testament to his scientific observation of light and geographical features.

surface modelling that normally characterize his peopled landscapes. Medieval optical science stressed that strong brightness and deep darkness distorted perception, as they lay outside the "range of moderateness".

He has meticulously registered what happens as the medieval "species" (images) weaken on their journey through the air. The detail visible in the twiggy trees is systematically graded according to the distance from the viewer's eye. Atmosphere progressively leaches out colour and veils the extreme distance. The silhouetted manikins lose the definition of their limbs as they move farther away. Remarkably, Bruegel notes that the dark reflections below the figures on the ice do not begin exactly at their feet, but are separated by a thin layer of sheen.

These are just the kind of effects mastered by Ibn-al-Haytham, the great student of optics in eleventh-century Egypt. Leonardo da Vinci's writings on the optical effects of glare, shine, contrast, motion, distance and atmosphere depend on the tradition established by al-Haytham. We know little about Bruegel's intellectual engagements, but he had been to Italy and had undoubtedly encountered theorizing artists who sought a science of seeing in pictures. His paintings themselves testify that his profound and systematic observations of light in nature were no less intense than Leonardo's.

Ortelius, for his part, was no simple map maker. His great atlas, Theatrum Orbis Terrarum (Theatre of the Globe of the World, 1570), was deeply concerned with historical, economic and social geography. He used evidence of early maps to chart the biblical lands and historic journeys. He critically collated historical accounts, not least by the great classical writers, of the characters of the lands and their peoples, comparing them to modern observations.

Of the Dutch themselves, he immodestly claims that "as long as anyone respects their homely and plain manners, there is no nation more prone to be civil, courteous and humane, or one in which you will find less cruelty, bad temper or strictness; they are good-natured, plain, devoid of all treachery and guile, and not inclined to notorious vices".

Bruegel brings his analytical eye to bear on his magnificent portraits of the land and its inhabitants. Ortelius brings maps into the orbit of the great historical story of Earth and its peoples. Their friendship clearly went beyond compatible personalities and respect for each other's professional skills. They shared ways of conveying the human condition.

Martin Kemp is emeritus professor in history of art at the University of Oxford, Oxford, UK. 